Article

\title{
Xanthine Oxidase Inhibitory Potential, Antioxidant and Antibacterial Activities of Cordyceps militaris (L.) Link Fruiting Body
}

\author{
Tran Ngoc Quy and Tran Dang Xuan *(1) \\ Graduate school for International Development and Cooperation, Hiroshima University, \\ Hiroshima 739-8529, Japan; tnquy@ctu.edu.vn \\ * Correspondence: tdxuan@hiroshima-u.ac.jp; Tel./Fax: +81-82-424-6927
}

Received: 10 January 2019; Accepted: 28 January 2019; Published: 29 January 2019

check for updates

\begin{abstract}
Background: Cordyceps militaris is a medicinal mushroom and has been extensively used as a folk medicine in East Asia. In this study, the separation of constituents involved in xanthine oxidase $(\mathrm{XO})$ inhibitory, antioxidant and antibacterial properties of $C$. militaris was conducted. Methods: The aqueous residue of this fungus was extracted by methanol and then subsequently fractionated by hexane, chloroform, ethyl acetate and water. The ethyl acetate extract possessed the highest XO inhibitory and antioxidant activities was separated to different fractions by column chromatography. Each fraction was then subjected to anti-hyperuricemia, antioxidant and antibacterial assays. Results: The results showed that the $\mathrm{CM} 8$ fraction exhibited the strongest $\mathrm{XO}$ inhibitory activity (the lowest $\mathrm{IC}_{50}: 62.82 \mu \mathrm{g} / \mathrm{mL}$ ), followed by the CM10 (IC $50: 68.04 \mu \mathrm{g} / \mathrm{mL}$ ) and the CM7 ( $\mathrm{IC}_{50}: 86.78 \mu \mathrm{g} / \mathrm{mL}$ ). The level of $\mathrm{XO}$ inhibition was proportional to antioxidant activity. In antibacterial assay, the CM9 and CM11 fractions showed effective antibacterial activity (MIC values: $15-25 \mathrm{mg} / \mathrm{mL}$ and $10-25 \mathrm{mg} / \mathrm{mL}$, respectively). Results from gas chromatography-mass spectrometry (GC-MS) analyses indicated that cordycepin was the major constituent in the CM8 and CM10 fractions. Conclusions: This study revealed that $C$. militaris was beneficial for treatment hyperuricemia although in vivo trials on compounds purified from this medicinal fungus are needed.
\end{abstract}

Keywords: Cordyceps militaris; xanthine oxidase; antioxidant; antibacterial; cordycepin; GC-MS

\section{Introduction}

Species in the genus Cordyceps are considered as valuable traditional medicines and other medical applications worldwide, especially in East Asia countries [1,2]. Among them, Cordyceps militaris (L.) Link is an ancient medicinal tonic and the most of $C$. militaris nowadays is produced by various modern culture techniques [3]. C. militaris exhibited a wide spectrum of clinical health benefits including antifatigue and antistress [4]; anti-inflammatory [5]; antiviral [6]; antifungal and anticancer [7]; HIV-1 protease inhibitory [8]; antioxidant [9]; anti-microbial [10]; inhibition high-fat diet metabolic disorders [11]; immunomodulatory [12]; anti-tumor and anti-metastatic activities [13].

Furthermore, the hot water extract of $C$. militaris has been reported to contain various important bioactive compounds such as cordycepin, adenosine, polysaccharides, fatty acids, mannitol, amino acids, trace elements, ash, fiber and other chemical compositions [7,9,10,14-17]. Many researchers noted that cordycepin ( $3^{\prime}$-deoxyadenosine) is an important and active metabolite [2,18]. The fermented broth of $C$. militaris obtains clinical effects such as the prevention of alcohol-induced hepatotoxicity [19], inhibitory effects on proliferation and apoptotic cell death for human brain cancer cells [20], inhibitory effects on LPS-induced acute lung injury [21], anti-hyperglycemia [22], anti-tumor and anti-metastatic activities [17]. Adenosine, another bioactive chemical of C. militaris, has a number of pharmacological 
functions such as cardio-protective and therapeutic agents for chronic heart failure, a homeostatic modulator in the central nervous system [16], antioxidant and HIV-1 protease inhibitory [8]. C. militaris also exhibited antifungal [23,24], cytotoxic activity [25], antibacterial, anti-tumor agents [13] and plasma glucose reduction [26]. However, the xanthine inhibitory activity of this fungus has not been comprehensively examined.

Nowadays, hyperuricemia, a pre-disposing factor of gout, has been recognized as a lifestyle syndrome that affects the adult population in the developed as well as developing countries [27]. Gout is induced by overproduction or under-excretion of uric acid. It is caused by a high dietary intake of foods containing high amounts of nucleic acids, such as some types of seafood, meats (especially organ meats) and yeasts [28]. Xanthine oxidase (XO) is considered as a cause of hyperuricemia. The acute hyperuricemia can lead to the development of gout, hypertension, diabetes, chronic heart failure, atherosclerosis and hyperlipidemia [29]. Until now, only allopurinol and febuxostat have been clinically approved as $\mathrm{XO}$ inhibitors to treat hyperuricemia and gout. However, they also result in many undesirable effects such as hypersensitivity syndrome, hepatitis nephropathy, eosinophilia, vasculitis, fever, and skin rash [30,31].

The discovery of compounds possessing XO inhibitory is necessary to avoid such adverse effects of allopurinol and febuxostat. Yong et al. [29] found that hot water extract of $C$. militaris exhibited significant anti-hyperuricemic action but active components for this activity were not determined. Additionally, the investigation on antibacterial performance of aqueous extracts of $C$. militaris has been proceeded but bioactive compounds from the methanolic extract have not been elaborated [32-35]. Infectious diseases caused by bacteria are still the major reason of illness and death in developing countries [36]. Gastroenteritis and urinary tract infection were predominated by bacteria such as Escherichia coli, Staphylococcus aureus, Proteus mirabilis, and Bacillus subtilis [37,38]. Many plant extracts have been found as nutritionally safe and easily degradable source of antibacterial agents against human pathogens [39]. Hence, this study was conducted to investigate the xanthine oxidase inhibitory and determine the correlation to the antioxidant and antibacterial properties of the folk medicine C. militaris. The analyses of bioactive constituents from this medicinal mushroom were also conducted.

\section{Materials and Methods}

\subsection{Chemicals}

Methanol, hexane, chloroform, ethyl acetate and ethanol were purchased from Junsei Chemical Co., Ltd., Tokyo, Japan. Potassium phosphate monobasic and dibasic, xanthine, xanthine oxidase, allopurinol, and hydrochloric acid were obtained from Sigma-Aldrich Corp., St. Louis, MO, USA. Reagents including 1,1-diphenyl-2-picrylhydrazyl (DPPH), sodium acetate, acetic acid, 2,2'-azinobis (3-ethylbenzothiazoline-6-sulfonic acid) (ABTS), potassium peroxodisulfate, and dibutyl hydroxytoluene (BHT) were supplied by Kanto Chemical Co. Inc., Tokyo, Japan. Four bacteria including Staphylococcus aureus, Escherichia coli, Bacillus subtilis, and Proteus mirabilis were provided by Sigma-Aldrich Corp., St. Louis, MO USA. All chemicals used were of analytical grade.

\subsection{Plant Materials and Samples Preparation}

The dried and sterilized fruiting bodies of C. militaris were provided by Truc Anh Company, Bac Lieu city, Vietnam. Fruiting body at green house of Truc Anh Company in the South of Vietnam were harvested and dried by freeze-drying machine (Mactech MSL1000, $15^{\circ} \mathrm{C}$ ) and packaged on April 18th, 2017. The sample was transferred to the Laboratory of Plant Physiology and Biochemistry, Graduate School for International Development and Cooperation (IDEC), Hiroshima University, Higashi-Hiroshima, Japan for further analysis. 


\subsection{Preparation of Plant Extract}

The whole fruiting body of $C$. militaris was soaked in water for $12 \mathrm{~h}$ at room temperature and dried in a convection oven (MOV-212F (U), Sanyo, Japan) at $50{ }^{\circ} \mathrm{C}$ for $2 \mathrm{~d}$ before pulverized into powder using a grinding machine. The powder $(1.0 \mathrm{~kg})$ was immersed in $15 \mathrm{~L}$ methanol $(\mathrm{MeOH})$ for two weeks at room temperature. After that, the filtrate from powder-methanol dispersion was concentrated under vacuum at $45^{\circ} \mathrm{C}$ using a rotary evaporator (SB-350-EYELA, Tokyo Rikakikai Co., Ltd., Tokyo, Japan) to produce $126.14 \mathrm{~g}$ of crude extract. The crude extract was suspended in distilled water $(500 \mathrm{~mL})$ and successively fractionated with hexane, chloroform $\left(\mathrm{CHCl}_{3}\right)$ and ethyl acetate (EtOAc) to produce 10.24, $19.25,50.21$, and 20.17 g extracts, respectively. The extract with the highest xanthine oxidase inhibitory and antioxidant activities was used for further separation by column chromatography.

\subsection{Fractionation of Ethyl Acetate Fraction}

The EtOAc extract (16.28 g) possessed the highest xanthine oxidase inhibitory and antioxidant on a preliminary test was subjected to a normal-phase of column chromatography (40 mm diameter $\times 600$ mm height, Climbing G2, Mixell, Tokyo, Japan) filled with silica gel (size Á 60, 200-400 mesh particle size, Sigma-Aldrich, Tokyo, Japan). This process yielded 14 fractions by increasing the polarity by $\mathrm{MeOH}$ with $\mathrm{CHCl}_{3}$ of the following eluents: $\mathrm{CM} 1$ in $\mathrm{CHCl}_{3}, \mathrm{CM} 2$ in $\mathrm{CHCl}_{3}: \mathrm{MeOH}$ (9.9:0.1), $\mathrm{CM} 3$ in $\mathrm{CHCl}_{3}: \mathrm{MeOH}$ (9.8:0.2), CM4 in $\mathrm{CHCl}_{3}: \mathrm{MeOH}$ (9.6:0.4), CM5 in $\mathrm{CHCl}_{3}: \mathrm{MeOH}$ (9.4:0.6), CM6 in $\mathrm{CHCl}_{3}: \mathrm{MeOH}$ (9.2:0.8), CM7 in $\mathrm{CHCl}_{3}: \mathrm{MeOH}$ (9:1), CM8 in $\mathrm{CHCl}_{3}: \mathrm{MeOH}$ (8.8:1.2), CM9 in $\mathrm{CHCl}_{3}: \mathrm{MeOH}(8.6: 1.4), \mathrm{CM} 10$ in $\mathrm{CHCl}_{3}: \mathrm{MeOH}$ (8.4:1.6), CM11 in $\mathrm{CHCl}_{3}: \mathrm{MeOH}$ (8:2), CM12 in $\mathrm{CHCl}_{3}: \mathrm{MeOH}(7: 3), \mathrm{CM}_{13}$ in $\mathrm{CHCl}_{3}: \mathrm{MeOH}(1: 1)$, and $\mathrm{CM} 14$ in $\mathrm{CHCl}_{3}: \mathrm{MeOH}$ (4:6).

\subsection{Xanthine Oxidase (XO) Inhibitory Activity}

The XO inhibitory activity was examined spectrophotometrically in aerobic conditions as described previously [40] with some adjustments. The assay mixture consisted of $50 \mu \mathrm{L}$ of tests solution $(6.25-100.00 \mu \mathrm{g} / \mathrm{mL}), 30 \mu \mathrm{L}$ of $70 \mathrm{mM}$ phosphate buffer $(\mathrm{pH}=7.5)$ and $30 \mu \mathrm{L}$ of enzyme solution (0.01 units / $\mathrm{mL}$ in $70 \mathrm{mM}$ phosphate buffer, $\mathrm{pH}=7.5$ ), which were prepared immediately before use. After pre-incubation at $25^{\circ} \mathrm{C}$ for $15 \mathrm{~min}$, reaction was initiated by addition of $60 \mu \mathrm{L}$ of substrate solution ( $150 \mu \mathrm{M}$ xanthine in buffer). After that, the assay mixture was incubated at $25^{\circ} \mathrm{C}$ for $30 \mathrm{~min}$. The reaction was stopped by adding $25 \mu \mathrm{L}$ of $1 \mathrm{~N}$ hydrochloric acid $(\mathrm{HCl})$ and the absorbance was measured at $290 \mathrm{~nm}$ by using a microplate reader (Multiskan ${ }^{\mathrm{TM}}$ Microplate Spectrophotometer, Thermo Fisher Scientific, Osaka, Japan). A blank was prepared in similar way but the enzyme solution was accumulated to the assay mixture after the solution of $1 \mathrm{~N} \mathrm{HCl}$ added. One unit of XO was defined as the amount of enzyme that required to produce $1 \mu \mathrm{mol}$ of uric acid per min at $25^{\circ} \mathrm{C}$.

The XO inhibitory activity was calculated by this formula (1):

$$
\% \text { Inhibition }=\left\{\frac{(\mathrm{A}-\mathrm{B})-(\mathrm{C}-\mathrm{D})}{(\mathrm{A}-\mathrm{B})}\right\} \times 100
$$

where A was the activity of the enzyme without test extracts or fractions, B was the control of A without test extracts or fractions and enzyme. $\mathrm{C}$ and $\mathrm{D}$ were the activities of the test solutions with and without $\mathrm{XO}$. The values of $\mathrm{IC}_{50}$ were calculated from the means of the spectrophotometric data of the test trials repeated 5 times. The test solutions were dissolved in DMSO (dimethyl sulfoxide) followed by dilution with buffer. The final concentration of DMSO was less than $0.25 \%$. Allopurinol at 6.25 , $12.5,25,50,100 \mu \mathrm{g} / \mathrm{mL}$ dilutions were used as a positive control.

\subsection{Antibacterial Activity}

The evaluation of antibacterial activity was based on a method described previously [41]. All bacterial strains were cultured in a Luria-Bertani (LB) broth for $24 \mathrm{~h}$ at $37^{\circ} \mathrm{C}$. The four bacterial strains employed in this experiment included Staphylococcus aureus, Escherichia coli, Bacillus subtilis 
and Proteus mirabilis. The final population was standardized to be $1.29 \times 10^{6} \mathrm{CFU} / \mathrm{mL}$ (S. aureus), $1.45 \times 10^{6} \mathrm{CFU} / \mathrm{mL}$ (E. coli), $1.63 \times 10^{6} \mathrm{CFU} / \mathrm{mL}$ (B. subtilis) and $2.87 \times 10^{6} \mathrm{CFU} / \mathrm{mL}$ (P. mirabilis). An amount of $0.1 \mathrm{~mL}$ of the bacteria suspension was spread over the surface of the solid LB agar medium in Petri dish (9 $\mathrm{cm}$ in diameter). After that, filter paper discs $(6 \mathrm{~mm}$ diameter) loaded with $20 \mu \mathrm{L}$ of each extract or fraction sample (with a concentration $40 \mathrm{mg} / \mathrm{mL}$ in DMSO) were placed on the surface of the LB agar plates. The Petri dishes were incubated at $37{ }^{\circ} \mathrm{C}$ for $24 \mathrm{~h}$ and then the inhibition zone was measured. Ampicillin and streptomycin were used as the positive controls. The concentrations of the fractions included 1.25, 1.5, 2.5, 5, 10, 20, 25, 30, and $40 \mathrm{mg} / \mathrm{mL}$ ). The lowest concentration that inhibited the visible bacterial growth was evaluated as minimal inhibitory concentration (MIC). Ampicillin and streptomycin (1.25, 0.625, 0.313, 0.156, 0.078, 0.039, 0.0195, 0.0097, $0.0048,0.0024,0.0012$, and $0.0006 \mathrm{mg} / \mathrm{mL}$ ) were used as positive controls. Subsequently, DMSO was used as a negative control.

\subsection{Antioxidant Activity}

\subsubsection{DPPH Radical Scavenging Activity}

The antioxidant activity of the extracts and achieved fractions were determined by using 2,2-Diphenyl1-picrylhydrazyl (DPPH) free radical scavenging method as described previously [42] with some adjustments. Briefly, an amount of $100 \mu \mathrm{L}$ samples was mixed with $50 \mu \mathrm{L}$ of $0.5 \mathrm{mM} \mathrm{DPPH}$ and $100 \mu \mathrm{L}$ of $0.1 \mathrm{M}$ acetate buffer ( $\mathrm{pH}$ 5.5). After mixing, the mixtures were maintained in the dark at room temperature for $30 \mathrm{~min}$. The reduction of the DPPH radical was measured at $517 \mathrm{~nm}$ using a microplate reader. BHT standard solutions $(0.001-0.05 \mathrm{mg} / \mathrm{mL})$ were used as positive controls (2).

$$
\text { DPPH radical scavenging activity }(\%)=\left[\left\{\mathrm{A}_{\text {control }}-\left(\mathrm{A}_{\text {sample }}-\mathrm{A}_{\text {blank sample }}\right)\right\} / \mathrm{A}_{\text {control }}\right] \times 100
$$

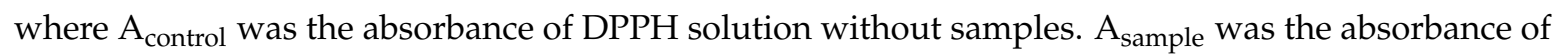

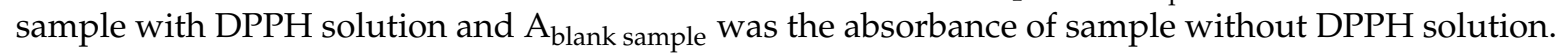
Lower absorbance showed higher $\mathrm{DPPH}$ radical scavenging activity. The $\mathrm{IC}_{50}$ (inhibitory concentration) value was determined as the concentration required to decrease the initial DPPH radical concentration by $50 \%$. Therefore, the lower $\mathrm{IC}_{50}$ value indicated higher $\mathrm{DPPH}$ radical scavenging activity.

\subsubsection{ABTS Radical Scavenging Activity}

The ABTS radical cation decolorization assay was carried out as an improved ABTS method mentioned noted previously [43] with some modifications. Briefly, the ABTS radical solution was prepared by mixing $7 \mathrm{mM}$ ABTS [2,20-azinobis (3-ethylbenzothiazoline-6-sulfonic acid)] and 2.45 $\mathrm{mM}$ potassium persulfate in water. After that, this solution was incubated in the dark at room temperature for $16 \mathrm{~h}$ and then diluted with methanol to obtain an absorbance of $0.70 \pm 0.05$ at $734 \mathrm{~nm}$. An aliquot of $120 \mu \mathrm{L}$ of the ABTS solution was mixed with $24 \mu \mathrm{L}$ of samples and the mixture was incubated in the dark at room temperature for $30 \mathrm{~min}$. The absorbance of reaction was recorded at $734 \mathrm{~nm}$ using a microplate reader. BHT standard $(0.01-0.25 \mathrm{mg} / \mathrm{mL})$ was used as a reference. The percentage inhibition was calculated according to the formula (3):

$$
\text { ABTS radical scavenging activity }(\%)=\left[\left\{\mathrm{A}_{\text {control }}-\left(\mathrm{A}_{\text {sample }}-\mathrm{A}_{\text {blank sample }}\right)\right\} / \mathrm{A}_{\text {control }}\right] \times 100
$$

The $A_{\text {control }}$ was the absorbance of ABTS radical solution without samples. $A_{\text {sample }}$ was the absorbance of ABTS radical solution with samples and $A_{\text {blank sample was the absorbance of sample }}$ without ABTS radical solution. A lower absorbance therefore indicated higher ABTS radical scavenging activity. The $\mathrm{IC}_{50}$ (inhibitory concentration) value was calculated as the concentration needed to scavenge $50 \%$ of ABTS. As a result, lower $\mathrm{IC}_{50}$ value showed higher antioxidant activity. 


\subsection{Identification of Chemical Constituents by Gas Chromatography-Mass Spectrometry (GC-MS)}

A volume of $1 \mu \mathrm{L}$ aliquot of each C. militaris fraction was injected into a GC-MS system (JMS-T100 GCV, JEOL Ltd., Tokyo, Japan). The column employed in this experiment was DB-5MS column (length $30 \mathrm{~m}$, internal diameter $0.25 \mathrm{~mm}$, thickness $0.25 \mu \mathrm{m}$ ) (Agilent Technologies, J \& W Scientific Products, Folsom, CA, USA). The system uses helium as a carrier gas and the split ratio was 5.0/1.0. The temperature program was set up in the GC oven as follows: the initial temperature at $50{ }^{\circ} \mathrm{C}$ without hold time, the programmed rate by $10^{\circ} \mathrm{C} / \mathrm{min}$ up to a final temperature of $300{ }^{\circ} \mathrm{C}$ with 20 min for hold time. The injector and detector temperatures were set at $300{ }^{\circ} \mathrm{C}$ and $320{ }^{\circ} \mathrm{C}$, respectively. The mass range scanned from 29-800 amu. The peak data set was collected by using the JEOL's GC-MS Mass Center System version 2.65a (JEOL Ltd., Tokyo, Japan) and by comparing detected peaks with National Institute of Standards and Technology (NIST) MS library [44].

\subsection{Statistical Analysis}

The data were statistically analyzed by one-way ANOVA using the Minitab 16.0 software (Minitab Inc., State College, PA, USA). The significant difference among means were determined by using Fisher's test with the confidence level of 95\% $(p<0.05)$. All experiments were carried out in triplicate and expressed as means \pm standard deviation (SD).

\section{Results}

\subsection{Xanthine Oxidase Inhibitory Activity of C. militaris Fractions}

Xanthine oxidase inhibition, which resulted in a decreased of uric acid production, was measured spectrophotometrically at $290 \mathrm{~nm}$. The ethyl acetate extract (EtOAc extract) showed an xanthine oxidase inhibition by $31.66 \%$ at $100 \mu \mathrm{g} / \mathrm{mL}$ concentration, whereas other extracts exhibited negligible inhibitions (Table 1).

Table 1. Xanthine oxidase inhibitory and antioxidant activities of C. militaris.

\begin{tabular}{|c|c|c|c|}
\hline \multirow{2}{*}{ Extracts } & \multirow{2}{*}{$\%$ XO Inhibition at $100 \mu \mathrm{g} / \mathrm{mL}$} & \multicolumn{2}{|c|}{ Antioxidant Activities } \\
\hline & & DPPH $\left(\mathrm{IC}_{50} \mathrm{mg} / \mathrm{mL}\right)$ & ABTS $\left(\mathrm{IC}_{50} \mathrm{mg} / \mathrm{mL}\right)$ \\
\hline Hexane $(\mathrm{H})$ & - & $3.07 \pm 0.04^{\mathrm{a}}$ & $4.45 \pm 0.06^{\mathrm{a}}$ \\
\hline Chloroform (C) & - & $1.65 \pm 0.15^{b}$ & $2.52 \pm 0.19^{b}$ \\
\hline Ethyl acetate $(\mathrm{E})$ & $31.66 \pm 2.86$ & $0.60 \pm 0.03^{d}$ & $1.03 \pm 0.02^{\mathrm{d}}$ \\
\hline Aqueous residue $(\mathrm{W})$ & - & $1.35 \pm 0.07^{\mathrm{c}}$ & $1.65 \pm 0.07^{\mathrm{c}}$ \\
\hline
\end{tabular}

Data presented means \pm standard deviation (SD). Values in a column with similar letters are not significantly different by Fisher's test $(p<0.05)$. -: not detected.

All of 14 fractions from the EtOAc extract were assessed for their xanthine oxidase inhibitory ability. Of them, eight fractions showed the presence of XO inhibition activity (Table 2). Furthermore, the percentage of XO inhibition of CM8 (52.58\%), CM7 (52.72\%), CM10 (56.56\%), and CM6 (61.70\%) fractions were found to be more active than other fractions. The $\mathrm{XO}$ inhibition were described by $\mathrm{IC}_{50}$ value and the lower $\mathrm{IC}_{50}$ indicated the higher $\mathrm{XO}$ inhibition activity. Therefore, the CM8 fraction possessed the most potential XO inhibition $\left(\mathrm{IC}_{50}, 62.82 \mu \mathrm{g} / \mathrm{mL}\right)$, followed by $\mathrm{CM} 10\left(\mathrm{IC}_{50}, 68.04 \mu \mathrm{g} / \mathrm{mL}\right)$, CM7 ( $\left.\mathrm{IC}_{50}, 86.78 \mu \mathrm{g} / \mathrm{mL}\right)$, and CM6 $\left(\mathrm{IC}_{50}, 87.73 \mu \mathrm{g} / \mathrm{mL}\right)$ fractions. Other fractions exhibited trivial inhibitory activities which were not considerable enough to calculate $\mathrm{IC}_{50}$ values. 
Table 2. Xanthine oxidase inhibitory activity of EtOAc fractions isolated from C. militaris.

\begin{tabular}{ccc}
\hline Fractions & \% XO Inhibition at $\mathbf{1 0 0} \boldsymbol{\mu g} / \mathbf{m L}$ & IC $_{50}$ Value $(\mu \mathrm{g} / \mathbf{m L})$ \\
\hline CM1 & - & - \\
CM2 & - & - \\
CM3 & - & - \\
CM4 & $21.88 \pm 0.78^{\mathrm{f}}$ & - \\
CM5 & $39.57 \pm 0.56^{\mathrm{d}}$ & - \\
CM6 & $61.70 \pm 0.64^{\mathrm{b}}$ & $87.73 \pm 0.81^{\mathrm{a}}$ \\
CM7 & $52.72 \pm 0.74^{\mathrm{c}}$ & $86.78 \pm 1.20^{\mathrm{a}}$ \\
CM8 & $52.58 \pm 1.55^{\mathrm{c}}$ & $62.82 \pm 4.48^{\mathrm{b}}$ \\
CM9 & $31.12 \pm 3.71^{\mathrm{e}}$ & - \\
CM10 & $56.56 \pm 2.95^{\mathrm{c}}$ & $68.04 \pm 5.85^{\mathrm{b}}$ \\
CM11 & - & - \\
CM12 & $11.92 \pm 1.79^{\mathrm{g}}$ & - \\
CM13 & - & - \\
CM14 & - & $4.85 \pm 2.19^{\mathrm{c}}$ \\
Allopurinol & $90.20 \pm 6.19^{\mathrm{a}}$ &
\end{tabular}

Data presented means \pm standard deviations (SD). Values in a column with similar letters are not significantly different $(p<0.05)$; -: not detected.

\subsection{Antioxidant Activities of C. militaris Fractions}

The antioxidant activities of $C$. militaris were evaluated using DPPH and ABTS tests, compared with the standard BHT in Figure 1. The antioxidant properties were described by $\mathrm{IC}_{50}$ value and the lower $\mathrm{IC}_{50}$ indicated the higher radical scavenging activity. Fourteen fractions obtained from C. militaris showed various levels of DPPH and ABTS scavenging capacity (Table 1), of which the fraction CM7 presented the strongest antioxidant activity in both DPPH and ABTS assays. Meanwhile, the antioxidant activity of CM5 was the lowest performance in Figure 1.

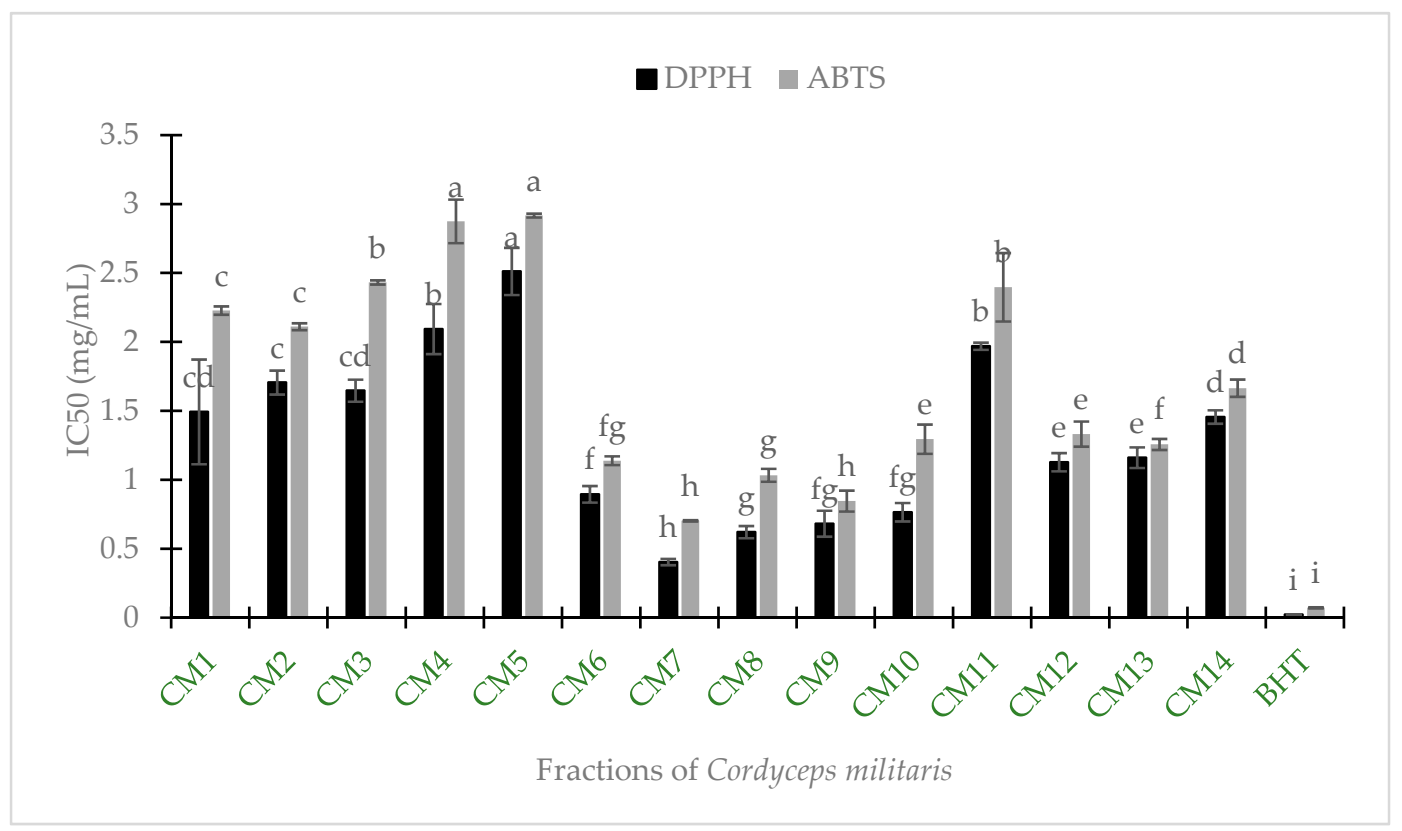

Figure 1. DPPH and ABTS radical scavenging activities of fractions from C. militaris and standard antioxidant butylated hydroxytoluene (BHT). Column with similar letters are not significantly different $(p<0.05)$.

In ABTS scavenging activity, the fractions CM7 and CM9 exposed the highest effective activity ( $\mathrm{IC}_{50}, 0.702 \mathrm{mg} / \mathrm{mL}$ and $0.845 \mathrm{mg} / \mathrm{mL}$, respectively), followed by the CM8 $\left(\mathrm{IC}_{50}, 1.032 \mathrm{mg} / \mathrm{mL}\right.$ ) and CM6 $\left(\mathrm{IC}_{50}, 1.138 \mathrm{mg} / \mathrm{mL}\right.$ ). In the DPPH assay, the CM8 was also potential but it was statistically 
similar to that of the CM9 and CM10. Overall, it was found the CM6, CM7, CM8, and CM9 possessed greater antioxidant capacities than other fractions.

\subsection{Antibacterial Activities of C. militaris Extracts}

The antibacterial activity of $C$. militaris was conducted on two Gram-positive (B. subtilis and S. aureus) and two Gram-negative (E. coli and P. mirabilis). Table 3 showed that levels of antibacterial activities versus four bacteria were varied among fractions. Both CM9 and CM11 were the most potential candidates to inhibit the growth of most tested bacteria (MIC, $15-25 \mathrm{mg} / \mathrm{mL}$ and $10-25 \mathrm{mg} / \mathrm{mL}$ ). All fractions showed a lower inhibition than that of streptomycin and ampicillin. Ampicillin and streptomycin provided MIC values of $0.0097-0.039$ and $0.078-0.156 \mathrm{mg} / \mathrm{mL}$ (Table 3).

Table 3. Antibacterial activity in term of MIC values of EtOAc fractions isolated from C. militaris.

\begin{tabular}{ccccc}
\hline \multirow{2}{*}{ Fractions } & \multicolumn{4}{c}{ Minimum Inhibitory Concentration $(\mathbf{m g} / \mathbf{m L})$} \\
\cline { 2 - 5 } & B. subtilis & S. auereus & E. coli & P. mirabilis \\
\hline CM1 & 25 & 25 & 30 & 25 \\
CM2 & 30 & 20 & 25 & 30 \\
CM3 & 30 & - & 30 & 30 \\
CM4 & - & - & - & - \\
CM5 & 30 & 30 & 30 & - \\
CM6 & 25 & 20 & - & - \\
CM7 & 25 & 30 & 25 & 30 \\
CM8 & - & 30 & 20 & - \\
CM9 & 15 & 25 & 25 & - \\
CM10 & - & 30 & 30 & 25 \\
CM11 & 10 & 25 & 15 & 30 \\
CM12 & 15 & 20 & 20 & - \\
CM13 & - & 20 & - & - \\
CM14 & - & 25 & - & - \\
DMSO & - & - & - & 0.0195 \\
Ampicillin & 0.0195 & 0.039 & 0.0097 & 0.156 \\
Streptomycin & 0.156 & 0.078 & 0.156 & \\
\hline
\end{tabular}

\subsection{GC-MS of Analysis of C. militaris}

Gas chromatographic-mass spectrometry (GC-MS) is a very powerful and reliable analytical technique for identifying the presence of constituents in complex mixtures [45]. The major active components of the principal 14 fractions were detected and identified by GC-MS (Supplementary Materials Figures S1-S14) and summarized in Table 4. Principal constituents from C. militaris included cordycepin (3'-deoxyadenosine), hexadecenoic acid and pentadecanal. (Table 4; Supplementary Materials Figures S1-S14).

Cordycepin, appeared as the main compound that was detected in fractions of CM8, CM9 and CM10, while pentadecanal was found in most of fractions (CM3-CM10). Additionally, fatty acids (hexadecanoic acid, methyl hexadecanoate and methyl 2-oxohexadecanoate) were distributed in the CM1, CM2, CM6, CM7, CM11, CM12, CM13 and CM14 fractions. (Table 4; Supplementary Materials Figures S1-S14). 
Table 4. Principal compounds identified from different fractions of C. militaris.

\begin{tabular}{|c|c|c|c|c|}
\hline No. & Major Constituents & $\begin{array}{l}\text { Retention Times } \\
\text { (min) }\end{array}$ & $\begin{array}{l}\text { Peak Area } \\
\quad(\%)\end{array}$ & Fractions \\
\hline \multirow{3}{*}{1} & 1) Methyl hexadecanoate & 16.72 & 5.95 & \multirow{3}{*}{ CM1 } \\
\hline & 2) Hexadecanoic acid & 17.09 & 17.08 & \\
\hline & 3) $(9 Z, 12 E)$-Octadeca-9,12-dienoic acid & 18.73 & 29.54 & \\
\hline \multirow{5}{*}{2} & 1) Methyl hexadecanoate & 16.72 & 2.23 & \multirow{5}{*}{ CM2 } \\
\hline & 2) Hexadecanoic acid & 17.11 & 20.64 & \\
\hline & 3) $(9 Z, 12 E)$-Octadeca-9,12-dienoic acid & 18.76 & 32.16 & \\
\hline & 4) $(9 R, 10 R, 13 R, 17 R)-17-[(E, 2 R, 5 R)-5,6-$ Dimethylhept-3- & & & \\
\hline & $\begin{array}{l}\text { en-2-yl]-10,13-dimethyl-1,2,9,11,12,15,16,17-octahydrocyclopenta } \\
\text { [a] phenanthren-3-one }\end{array}$ & 29.12 & 6.25 & \\
\hline \multirow{4}{*}{3} & 1) Pentadecanal & 14.56 & 16.02 & \multirow{4}{*}{ CM3 } \\
\hline & 2) Methyl 2-oxohexadecanoate & 17.41 & 3.04 & \\
\hline & 3) Octadecanal & 22.11 & 34.91 & \\
\hline & 4) Dodecanamide & 25.55 & 2.73 & \\
\hline \multirow{3}{*}{4} & 1) Pentadecanal & 14.56 & 10.38 & \multirow{3}{*}{ CM4 } \\
\hline & 2) Methyl 2-oxohexadecanoate & 17.40 & 3.20 & \\
\hline & 3) Octadecanal & 22.11 & 30.13 & \\
\hline \multirow{4}{*}{5} & 1) Pentadecanal & 14.56 & 7.11 & \multirow{4}{*}{ CM5 } \\
\hline & 2) Hexadecanal & 15.65 & 1.30 & \\
\hline & 3) Methyl 2-oxohexadecanoate & 17.41 & 3.22 & \\
\hline & 4) Octadecanal & 22.11 & 25.85 & \\
\hline \multirow{5}{*}{6} & $\begin{array}{l}\text { 1) }(1 R, 2 R, 3 S, 4 R)-3 \text {-Deuterio-6,8-dioxabicyclo [3.2.1] } \\
\text { octane-2,3,4-triol }\end{array}$ & 11.82 & 5.65 & \multirow{5}{*}{ CM6 } \\
\hline & 2) Pentadecanal & 14.56 & 53.80 & \\
\hline & 3) Hexadecanoic acid & 17.07 & 1.33 & \\
\hline & 4) Methyl 2-hydroxyhexadecanoate & 20.30 & 1.25 & \\
\hline & 5) Henicosan-1-ol & 26.33 & 1.99 & \\
\hline \multirow{5}{*}{7} & $\begin{array}{l}\text { 1) }(1 R, 2 R, 3 S, 4 R)-3-\text { Deuterio-6,8-dioxabicyclo [3.2.1] } \\
\text { octane-2,3,4-triol }\end{array}$ & 11.76 & 1.92 & \multirow{5}{*}{ CM7 } \\
\hline & 2) Pentadecanal & 14.52 & 21.35 & \\
\hline & 3) Hexadecanoic acid & 17.03 & 1.75 & \\
\hline & 4) Methyl 2-oxohexadecanoate & 17.37 & 1.26 & \\
\hline & 5) $\mathrm{N}$-(2-Hydroxyethyl) octanamide & 18.77 & 2.73 & \\
\hline \multirow{3}{*}{8} & $\begin{array}{l}\text { 1) }(1 R, 2 R, 3 S, 4 R)-3 \text {-Deuterio-6,8-dioxabicyclo [3.2.1] } \\
\text { octane-2,3,4-triol }\end{array}$ & 11.76 & 0.54 & \multirow{3}{*}{ CM8 } \\
\hline & 2) Pentadecanal & 14.52 & 19.79 & \\
\hline & 3) 3'-Deoxyadenosine & 21.98 & 55.38 & \\
\hline \multirow{3}{*}{9} & 1) Pentadecanal & 14.55 & 19.90 & \multirow{3}{*}{ CM9 } \\
\hline & 2) Methyl 2-oxohexadecanoate & 17.40 & 0.77 & \\
\hline & 3) 3'-Deoxyadenosine & 21.97 & 58.04 & \\
\hline \multirow{3}{*}{10} & 1) Tetradecanal & 13.39 & 0.83 & \multirow{3}{*}{ CM10 } \\
\hline & 2) Pentadecanal & 14.56 & 45.00 & \\
\hline & 3) 3'-Deoxyadenosine & 21.95 & 18.61 & \\
\hline \multirow{4}{*}{11} & 1) 2-hydroxybutanedioic acid & 6.18 & 1.89 & \\
\hline & 2) Hexadecanoic acid & 17.03 & 1.90 & \\
\hline & 3) $(11 E, 13 Z)$-Octadeca-1,11,13-triene & 18.67 & 0.72 & CM11 \\
\hline & 4) 1,3-Dihydroxypropan-2-yl hexadecanoate & 21.89 & 3.79 & \\
\hline & 1) Hexadecanoic acid & 17.03 & 1.41 & \\
\hline 12 & 2) $(11 E, 13 Z)$-Octadeca-1,11,13-triene & 17.68 & 1.27 & CM12 \\
\hline & 3) (1R)-1-Hexadecyl-2,3-dihydro- $1 H$-indene & 21.74 & 2.62 & \\
\hline & 1) Hexadecanoic acid & 17.02 & 4.18 & \\
\hline 13 & 2) $(11 E, 13 Z)$-Octadeca-1,11,13-triene & 18.67 & 15.71 & CM13 \\
\hline & 1) N,N-Dimethyl-1-undecanamine & 12.06 & 2.02 & \\
\hline 14 & 2) Hexadecanoic acid & 17.03 & 9.95 & CM14 \\
\hline & 3) $(11 E, 13 Z)$-Octadeca-1,11,13-triene & 18.76 & 25.50 & \\
\hline
\end{tabular}

\section{Discussion}

It was reported that the significant increase of gout and hyperuricemia principally caused by the changes in unusual habits of diet and exercise regimen [46]. The food with high content of nucleic acids such as meat and seafood raised the risk of gout disease. Hyperuricemia is a biochemical abnormality or metabolic disorder that results in development of gout and related oxidative stress-related diseases 
such as cancer, cardiovascular disease and a variety of other disorders [47]. Therefore, the lowering serum uric acid concentration within normal range is important and can be achieved by blocking the biosynthesis of uric acid [27]. Xanthine oxidase (XO) is a form of xanthine oxidoreductase, which has been discovered for decades. Natural XO inhibitors from plants are used in traditional herbal medicines for the treatment of gout or diseases associated with symptoms such as arthritis and inflammation [28]. From this fact, screening of $\mathrm{XO}$ inhibitory activity from medicinal plants might be an effective way to find new potential candidates for these major disease treatments. In this study, the xanthine oxidase inhibitory, antioxidant and antibacterial activities of $C$. militaris were determined. It was found that C. militaris obtained potent xanthine oxidase inhibitory, antioxidant and antibacterial properties and possessed rich phytochemicals which were characterized by column chromatography and GC-MS analyses (Tables 1-4).

Several previous studies showed that the majority of natural compounds that possessed XO inhibition belonged to lanostanoids [48], flavonoids [31], and phenolics [49]. From GC-MS results, cordycepin appeared as the major bioactive constituents in CM8, CM9, and CM10 fractions separated by column chromatography. Thus it was suggested that this compound may be responsible for the $\mathrm{XO}$ inhibition, although the purification of cordycepin as well as other bioactive components and examined for their XO inhibition is apparently required. Earlier researches showed that cordycepin obtained remarkable anti-hyperuricemic action in an in vivo model [50]. Thus, this research highlighted that cordycepin found C. militaris played a crucial role in inhibition of $\mathrm{XO}$ by an in vitro model. Oxidative stress results in human disease development or an abnormal immune response [9]. Furthermore, it was reported that free radicals caused oxidative damage to biomolecules and are responsible for progression of several diseases such as aging, cancer, inflammatory, diabetes, metabolic disorders, atherosclerosis and cardiovascular diseases [51]. Therefore, xanthine oxidase acted as a biological source of oxygen-derived free radical that led to cell and tissue damage [48]. Obviously, the XO inhibitory activity of $C$. militaris was attributed to their survival strategy to the oxidative stress. For example, several studies showed that polysaccharides from aqueous extracts of $C$. militaris possessed antioxidant properties [33-35] but there was little polysaccharide quantity found in methanolic extracts [25]. Furthermore, the in vitro antioxidant activity was reported to be correlated to cordycepin [21,52] and fatty acids [53]. The considerable amounts of cordycepin and fatty acids observed in CM7, CM8, CM9 and CM10 fractions by this study noticed that these compounds obtained in C. militaris might be responsible for significant antioxidant performance (Table 1; Figure 1) as found in previous reports [23,54].

The urinary tract infection and gastroenteritis have become a more serious problem today because of multidrug resistance to E. coli, S. aureus, P. mirabilis and B. subtilis infection $[37,38]$. In recent years, it was documented that methanolic extract of $C$. militaris had potential antibacterial activity $[23,25]$. To date, thousands of phytochemicals derived from plant extracts with various mechanisms of action have been identified as antibacterial compounds [55]. In this study, cordycepin appeared as the key component antibacterial activity, especially in E. coli and B. subtilis although further in vitro trial was needed. This study highlighted that $C$. militaris obtained potential substances which may be beneficial for the treatments of gout and bacterial infection. Several previous studies also indicated that fatty acids and the derivative methyl esters exhibited antibacterial activities $[53,56]$. The fatty acids with a chain length of more than 10 carbon atoms induced lysis of bacterial protoplasts. This mechanism could further distress the expression of bacterial virulence which played an important role in establishing infection [57]. Therefore, the presence of n-hexadecanoic acid (CM12, CM11, CM2, and CM1 fractions), hexadecanoic acid, 2-hydroxy-1-(hydroxymethyl) ethyl ester (CM11), hexadecanoic acid, 2-oxo-, methyl ester (CM9, CM7), hexadecanoic acid, methyl ester and 9,12-octadecadienoic acid methyl ester (Table 4) suggested that these constituents characterized by this study may be responsible for potent antibacterial activity of this medicinal fungus as reported by many previous reports $[58,59]$. This study has successfully separated fractions from C. militaris active on XO inhibitory, antioxidant and antibacterial activities separated by column chromatography and identified potent constituents by 
GC-MS analysis. However, the minimum bacteria concentration (MBC) should also be measured to achieve more efficacies on antibacterial activity. It was proposed that there were some compounds other than cordycepin and fatty acids in C. militaris can also be potential for pharmaceutical properties and needed further analyses.

\section{Conclusions}

This is the first study revealed that the medicinal fungus $C$. militaris possessed strong xanthine oxidase inhibition which may be potential for hyperuricemia treatment, although further in vivo trial is required. By employing separative techniques of column chromatography and GC-MS analyses, cordycepin, fatty acids and their derivatives appeared as the major compounds that may be responsible for antioxidant, antibacterial and anti-hyperuricemia activities as observed by this research. Findings of this study highlighted that $C$. militaris is potential to develop foods and drinks potential for treatment of hyperuricemia. Investigation of bioactive constituents purified from C. militaris on potent medicinal and pharmaceutical properties of this ancient fungus should be further elaborated.

Supplementary Materials: The following are available online at http:/ / www.mdpi.com/2305-6320/6/1/20/s1, Figure S1: GC-MS spectrum of fraction F1, Figure S2: GC-MS spectrum of fraction F2, Figure S3: GC-MS spectrum of fraction F3-6, Figure S4: GC-MS spectrum of fraction F7-12, Figure S5: GC-MS spectrum of fraction F13-16, Figure S6: GC-MS spectrum of fraction F17-24, Figure S7: GC-MS spectrum of fraction F25-30, Figure S8: GC-MS spectrum of fraction F31-35, Figure S9: GC-MS spectrum of fraction F36-42, Figure S10: GC-MS spectrum of fraction F43-47, Figure S11: GC-MS spectrum of fraction F48-52, Figure S12: GC-MS spectrum of fraction F53-58, Figure S13: GC-MS spectrum of fraction F59-62, Figure S14: GC-MS spectrum of fraction F63-70.

Author Contributions: T.D.X. and T.N.Q. conveyed the idea and carried out experiments. T.D.X. supervised the research and provided critical feedback to the manuscript. T.N.Q. wrote the manuscript and T.D.X. revised the paper. All authors approved the final version of the manuscript.

Funding: This research received no external funding.

Acknowledgments: The authors thanks to the financial support by Hiroshima University and the Ministry of Education and Training of Vietnam under the Hiroshima-VIED to provide a scholarship to Tran Ngoc Quy. Truc Anh Company (Bac Lieu city, Vietnam) was appreciated to kindly provide fruiting body of Cordyceps militaris. Thanks are also due to Do Tan Khang, Nguyen Van Quan, Truong Ngoc Minh and Yusuf Andriana for their assistance to this paper's preparation.

Conflicts of Interest: The authors declare no conflict of interest.

\section{References}

1. Shrestha, B.; Zhang, W.; Zhang, Y.; Liu, X. The medicinal fungus Cordyceps militaris: Research and development. Mycol. Prog. 2012, 11, 599-614. [CrossRef]

2. Dong, J.Z.; Wang, S.H.; Ai, X.R.; Yao, L.; Sun, Z.W.; Lei, C.; Wang, Y.; Wang, Q. Composition and characterization of cordyxanthins from Cordyceps militaris fruit bodies. J. Funct. Foods 2013, 5, 1450-1455. [CrossRef]

3. Das, S.K.; Matsuda, M.; Sakurai, A.; Sakakibara, M. Medicinal uses of the mushroom Cordyceps militaris: Current state and prospect. Fitoterapia 2010, 81, 961-968. [CrossRef]

4. Koh, J.H.; Kim, K.M.; Kim, J.M.; Song, J.C.; Suh, H.J. Antifatigue and antistress effect of the hot-water fraction from mycelia of Cordyceps sinensis. Biol. Pharm. Bull. 2003, 26, 691-694. [CrossRef] [PubMed]

5. Smiderle, F.R.; Baggio, C.H.; Borato, D.G.; Santana-Filho, A.P.; Sassaki, G.L.; Iacomini, M.; Van Griensven, L.J.L.D. Anti-inflammatory properties of the medicinal mushroom Cordyceps militaris might be related to its linear (1 $\rightarrow 3)$ - $\beta$-D-glucan. PLoS ONE 2014, 9, e110266. [CrossRef] [PubMed]

6. Ohta, Y.; Lee, J.B.; Hayashi, K.; Fujita, A.; Park, D.K.; Hayashi, T. In vivo anti-influenza virus activity of an immunomodulatory acidic polysaccharide isolated from Cordyceps militaris grown on germinated soybeans. J. Agric. Food Chem. 2007, 55, 10194-10199. [CrossRef]

7. Cho, S.H.; Kang, I.C. The inhibitory effect of cordycepin on the proliferation of cisplatin-resistant A549 lung cancer cells. Biochem. Biophys. Res. Commun. 2018, 498, 431-436. [CrossRef] 
8. Jiang, Y.; Wong, J.H.; Fu, M.; Ng, T.B.; Liu, Z.K.; Wang, C.R.; Li, N.; Qiao, W.T.; Wen, T.Y.; Liu, F. Isolation of adenosine, iso-sinensetin and dimethylguanosine with antioxidant and HIV-1 protease inhibiting activities from fruiting bodies of Cordyceps militaris. Phytomedicine 2011, 18, 189-193. [CrossRef]

9. Liu, J.Y.; Feng, C.P.; Li, X.; Chang, M.C.; Meng, J.L.; Xu, L.J. Immunomodulatory and antioxidative activity of Cordyceps militaris polysaccharides in mice. Int. J. Biol. Macromol. 2016, 86, 594-598. [CrossRef]

10. Zhou, X.; Cai, G.; He, Y.I.; Tong, G. Separation of cordycepin from Cordyceps militaris fermentation supernatant using preparative HPLC and evaluation of its antibacterial activity as an NAD ${ }^{+}$-dependent DNA ligase inhibitor. Exp. Ther. Med. 2016, 12, 1812-1816. [CrossRef]

11. Kim, S.B.; Ahn, B.; Kim, M.; Ji, H.J.; Shin, S.K.; Hong, I.P.; Kim, C.Y.; Hwang, B.Y.; Lee, M.K. Effect of Cordyceps militaris extract and active constituents on metabolic parameters of obesity induced by high-fat diet in C58BL/6J mice. J. Ethnopharmacol. 2014, 151, 478-484. [CrossRef] [PubMed]

12. Tuli, H.S.; Sharma, A.K.; Sandhu, S.S.; Kashyap, D. Cordycepin: A bioactive metabolite with therapeutic potential. Life Sci. 2013, 93, 863-869. [CrossRef] [PubMed]

13. Wada, T.; Sumardika, I.W.; Saito, S.; Ruma, I.M.W.; Kondo, E.; Shibukawa, M.; Sakaguchi, M. Identification of a novel component leading to anti-tumor activity besides the major ingredient cordycepin in Cordyceps militaris extract. J. Chromatogr. B Anal. Technol. Biomed. Life Sci. 2017, 1061-1062, 209-219. [CrossRef]

14. Hur, H. Chemical ingredients of Cordyceps militaris. Mycobiology 2008, 36, 233-235. [CrossRef]

15. Zhu, Z.Y.; Liu, F.; Gao, H.; Sun, H.; Meng, M.; Zhang, Y.M. Synthesis, characterization and antioxidant activity of selenium polysaccharide from Cordyceps militaris. Int. J. Biol. Macromol. 2016, 93, 1090-1099. [CrossRef]

16. Chiang, S.S.; Liang, Z.C.; Wang, Y.C.; Liang, C.H. Effect of light-emitting diodes on the production of cordycepin, mannitol and adenosine in solid-state fermented rice by Cordyceps militaris. J. Food Compost. Anal. 2017, 60, 51-56. [CrossRef]

17. Jin, Y.; Meng, X.; Qiu, Z.; Su, Y.; Yu, P.; Qu, P. Anti-tumor and anti-metastatic roles of cordycepin, one bioactive compound of Cordyceps militaris. Saudi J. Biol. Sci. 2018, 25, 991-995. [CrossRef] [PubMed]

18. Masuda, M.; Hatashita, M.; Fujihara, S.; Suzuki, Y.; Sakurai, A. Simple and efficient isolation of cordycepin from culture broth of a Cordyceps militaris mutant. J. Biosci. Bioeng. 2015, 120, 732-735. [CrossRef] [PubMed]

19. Cha, J.Y.; Ahn, H.Y.; Cho, Y.S.; Je, J.Y. Protective effect of cordycepin-enriched Cordyceps militaris on alcoholic hepatotoxicity in Sprague-Dawley rats. Food Chem. Toxicol. 2013, 60, 52-57. [CrossRef]

20. Chaicharoenaudomrung, N.; Jaroonwitchawan, T.; Noisa, P. Cordycepin induces apoptotic cell death of human brain cancer through the modulation of autophagy. Toxicol. In Vitro 2018, 46, 113-121. [CrossRef]

21. Lei, J.; Wei, Y.; Song, P.; Li, Y.; Zhang, T.; Feng, Q.; Xu, G. Cordycepin inhibits LPS-induced acute lung injury by inhibiting inflammation and oxidative stress. Eur. J. Pharmacol. 2018, 818, 110-114. [CrossRef] [PubMed]

22. Ma, L.; Zhang, S.; Du, M. Cordycepin from Cordyceps militaris prevents hyperglycemia in alloxan-induced diabetic mice. Nutr. Res. 2015, 35, 431-439. [CrossRef]

23. Reis, F.S.; Barros, L.; Calhelha, R.C.; Ćirić, A.; van Griensven, L.J.L.D.; Soković, M.; Ferreira, I.C.F.R. The methanolic extract of Cordyceps militaris (L.) Link fruiting body shows antioxidant, antibacterial, antifungal and antihuman tumor cell lines properties. Food Chem. Toxicol. 2013, 62, 91-98. [CrossRef]

24. Chen, R.; Jin, C.; Li, H.; Liu, Z.; Lu, J.; Li, S.; Yang, S. Ultrahigh pressure extraction of polysaccharides from Cordyceps militaris and evaluation of antioxidant activity. Sep. Purif. Technol. 2014, 134, 90-99. [CrossRef]

25. Dong, C.H.; Yang, T.; Lian, T. A Comparative study of the antimicrobial, antioxidant and cytotoxic activities of methanol extracts from fruit bodies and fermented mycelia of caterpillar medicinal mushroom Cordyceps militaris (Ascomycetes). Int. J. Med. Mushrooms 2014, 16, 485-495. [CrossRef] [PubMed]

26. Cheng, Y.W.; Chen, Y.I.; Tzeng, C.Y.; Chen, H.C.; Tsai, C.C.; Lee, Y.C.; Lin, J.G.; Lai, Y.K.; Chang, S.L. Extracts of Cordyceps militaris lower blood glucose via the stimulation of cholinergic activation and insulin secretion in normal rats. Phytother. Res. 2012, 26, 1173-1177. [CrossRef] [PubMed]

27. Kapoor, N.; Saxena, S. Xanthine oxidase inhibitory and antioxidant potential of Indian Muscodor species. 3 Biotech 2016, 6, 1-6. [CrossRef]

28. Nguyen, M.T.T.; Awale, S.; Tezuka, Y.; Le Tran, Q.; Watanabe, H.; Kadota, S. Xanthine oxidase inhibitory activity of Vietnamese medicinal plants. Biol. Pharm. Bull. 2004, 2, 1414-1421. [CrossRef]

29. Yong, T.; Zhang, M.; Chen, D.; Shuai, O.; Chen, S.; Su, J.; Chunwei, J.; Delong, F.; Xie, Y. Actions of water extract from Cordyceps militaris in hyperuricemic mice induced by potassium oxonate combined with hypoxanthine. J. Ethnopharmacol. 2016, 194, 403-411. [CrossRef] [PubMed] 
30. Liu, F.; Deng, C.; Cao, W.; Zeng, G.; Deng, X.; Zhou, Y. Phytochemicals of Pogostemon cablin (Blanco) Benth. aqueous extract: Their xanthine oxidase inhibitory activities. Biomed. Pharmacother. 2017, 89, 544-548. [CrossRef]

31. Santi, M.D.; Paulino Zunini, M.; Vera, B.; Bouzidi, C.; Dumontet, V.; Abin-Carriquiry, A.; Grougnet, R.; Ortega, M.G. Xanthine oxidase inhibitory activity of natural and hemisynthetic flavonoids from Gardenia oudiepe (Rubiaceae) in vitro and molecular docking studies. Eur. J. Med. Chem. 2018, 143, 577-582. [CrossRef] [PubMed]

32. Zhan, Y.; Dong, C.; Yao, Y. Antioxidant activities of aqueous extract from cultivated fruit-bodies of Cordyceps militaris (L.) Link in vitro. J. Integr. Plant Biol. 2006, 48, 1365-1370. [CrossRef]

33. Yu, R.; Yang, W.; Song, L.; Yan, C.; Zhang, Z.; Zhao, Y. Structural characterization and antioxidant activity of a polysaccharide from the fruiting bodies of cultured Cordyceps militaris. Carbohydr. Polym. 2007, 70, 430-436. [CrossRef]

34. Fengyao, W.; Hui, Y.; Xiaoning, M.; Junqing, J.; Guozheng, Z.; Xijie, G.; Zhongzheng, G. Structural characterization and antioxidant activity of purified polysaccharide from cultured Cordyceps militaris. Afr. J. Microbiol. Res. 2011, 5, 2743-2751. [CrossRef]

35. Chen, X.; Wu, G.; Huang, Z. Structural analysis and antioxidant activities of polysaccharides from cultured Cordyceps militaris. Int. J. Biol. Macromol. 2013, 58, 18-22. [CrossRef] [PubMed]

36. Dzotam, J.K.; Touani, F.K.; Kuete, V. Antibacterial activities of the methanol extracts of Canarium schweinfurthii and four other Cameroonian dietary plants against multi-drug resistant Gram-negative bacteria. Saudi J. Biol. Sci. 2016, 23, 565-570. [CrossRef]

37. Chimnoi, N.; Reuk-ngam, N.; Chuysinuan, P.; Khlaychan, P.; Khunnawutmanotham, N.; Chokchaichamnankit, D.; Thamniyom, W.; Klayraung, S.; Mahidol, C.; Techasakul, S. Characterization of essential oil from Ocimum gratissimum leaves: Antibacterial and mode of action against selected gastroenteritis pathogens. Microb. Pathog. 2018, 118, 290-300. [CrossRef]

38. Mishra, M.P.; Rath, S.; Swain, S.S.; Ghosh, G.; Das, D.; Padhy, R.N. In vitro antibacterial activity of crude extracts of 9 selected medicinal plants against UTI causing MDR bacteria. J. King Saud Univ. Sci. 2017, 29, 84-95. [CrossRef]

39. Mostafa, A.A.; Al-Askar, A.A.; Almaary, K.S.; Dawoud, T.M.; Sholkamy, E.N.; Bakri, M.M. Antimicrobial activity of some plant extracts against bacterial strains causing food poisoning diseases. Saudi J. Biol. Sci. 2018, 25, 253-258. [CrossRef]

40. Umamaheswari, M.; AsokKumar, K.; Somasundaram, A.; Sivashanmugam, T.; Subhadradevi, V.; Ravi, T.K. Xanthine oxidase inhibitory activity of some Indian medical plants. J. Ethnopharmacol. 2007, 109, 547-551. [CrossRef]

41. Fukuta, M.; Xuan, T.D.; Deba, F.; Tawata, S.; Khanh, T.D.; Chung, I.M. Comparative efficacies in vitro of antibacterial, fungicidal, antioxidant and herbicidal activities of momilatones A and B. J. Plant Interact. 2007, 2, 245-251. [CrossRef]

42. Elzaawely, A.A.; Xuan, T.D.; Tawata, S. Essential oils, kava pyrones and phenolic compounds from leaves and rhizomes of Alpinia zerumbet (Pers.) B.L. Burtt. \& R.M. Sm. and their antioxidant activity. Food Chem. 2007, 103, 486-494. [CrossRef]

43. Mikulic-Petkovsek, M.; Samoticha, J.; Eler, K.; Stampar, F.; Veberic, R. Traditional elderflower beverages: A rich source of phenolic compounds with high antioxidant activity. J. Agric. Food Chem. 2015, 63, 1477-1487. [CrossRef] [PubMed]

44. Andriana, Y.; Xuan, T.D.; Quan, N.V.; Quy, T.N. Allelopathic potential of Tridax procumbens L. on radish and identification of allelochemicals. Allelopath. J. 2018, 43, 222-238. [CrossRef]

45. Xuan, T.D.; Yulianto, R.; Andriana, Y.; Khanh, T.D. Chemical profile, antioxidant activities and allelopathic potential of liquid waste from germinated brown rice. Allelopath. J. 2018, 45, 1-12. [CrossRef]

46. Nile, S.H.; Park, S.W. Chromatographic analysis, antioxidant, anti-inflammatory and xanthine oxidase inhibitory activities of ginger extracts and its reference compounds. Ind. Crops Prod. 2015, 70, 238-244. [CrossRef]

47. Kapoor, N.; Saxena, S. Potential xanthine oxidase inhibitory activity of endophytic Lasiodiplodia pseudotheobromae. Appl. Biochem. Biotechnol. 2014, 173, 1360-1374. [CrossRef]

48. Lin, K.W.; Chen, Y.T.; Yang, S.C.; Wei, B.L.; Hung, C.F.; Lin, C.N. Xanthine oxidase inhibitory lanostanoids from Ganoderma tsugae. Fitoterapia 2013, 89, 231-238. [CrossRef] 
49. Gawlik-Dziki, U.; Dziki, D.; Świeca, M.; Nowak, R. Mechanism of action and interactions between xanthine oxidase inhibitors derived from natural sources of chlorogenic and ferulic acids. Food Chem. 2017, 225, 138-145. [CrossRef]

50. Yong, T.; Chen, S.; Xie, Y.; Chen, D.; Su, J.; Shuai, O.; Jiao, C.; Zuo, D. Cordycepin, a characteristic bioactive constituent in Cordyceps militaris, ameliorates hyperuricemia through URAT1 in hyperuricemic mice. Front. Microbiol. 2018, 9, 1-12. [CrossRef]

51. Ouyang, H.; Hou, K.; Peng, W.; Liu, Z.; Deng, H. Antioxidant and xanthine oxidase inhibitory activities of total polyphenols from onion. Saudi J. Biol. Sci. 2017, 25, 1509-1513. [CrossRef] [PubMed]

52. Olatunji, O.J.; Feng, Y.; Olatunji, O.O.; Tang, J.; Ouyang, Z.; Su, Z. Cordycepin protects PC12 cells against 6-hydroxydopamine induced neurotoxicity via its antioxidant properties. Biomed. Pharmacother. 2016, 81, 7-14. [CrossRef] [PubMed]

53. Karimi, E.; Ze Jaafar, H.; Ghasemzadeh, A.; Ebrahimi, M. Fatty acid composition, antioxidant and antibacterial properties of the microwave aqueous extract of three varieties of Labisia pumila Benth. Biol. Res. 2015, 48, 1-6. [CrossRef] [PubMed]

54. Yu, H.M.; Wang, B.S.; Huang, S.C.; Duh, P.D. Comparison of protective effects between cultured Cordyceps militaris and natural Cordyceps sinensis against oxidative damage. J. Agric. Food Chem. 2006, 54, 3132-3138. [CrossRef] [PubMed]

55. Barbieri, R.; Coppo, E.; Marchese, A.; Daglia, M.; Sobarzo-Sánchez, E.; Nabavi, S.F.; Nabavi, S.M. Phytochemicals for human disease: An update on plant-derived compounds antibacterial activity. Microbiol. Res. 2017, 196, 44-68. [CrossRef] [PubMed]

56. Huang, C.B.; Alimova, Y.; Myers, T.M.; Ebersole, J.L. Short- and medium-chain fatty acids exhibit antimicrobial activity for oral microorganisms. Arch. Oral Biol. 2011, 56, 650-654. [CrossRef]

57. Mohy El-Din, S.M.; El-Ahwany, A.M.D. Bioactivity and phytochemical constituents of marine red seaweeds (Jania rubens, Corallina mediterranea and Pterocladia capillacea). J. Taibah Univ. Sci. 2016, 10, 471-484. [CrossRef]

58. Eleazu, C.O. Characterization of the natural products in cocoyam (Colocasia esculenta) using GC-MS. Pharm. Biol. 2016, 54, 2880-2885. [CrossRef]

59. Al-Abd, N.M.; Nor, Z.M.; Mansor, M.; Zajmi, A.; Hasan, M.S.; Azhar, F.; Kassim, M. Phytochemical constituents, antioxidant and antibacterial activities of methanolic extract of Ardisia elliptica. Asian Pac. J. Trop. Med. 2017, 7, 569-576. [CrossRef]

(C) 2019 by the authors. Licensee MDPI, Basel, Switzerland. This article is an open access article distributed under the terms and conditions of the Creative Commons Attribution (CC BY) license (http://creativecommons.org/licenses/by/4.0/). 